\title{
Assessment of Estrogen Receptor Expression in Epithelial Ovarian Cancer Patients Using $16 \alpha-{ }^{18}$ F-Fluoro-17 $\beta$ - Estradiol PET/CT
}

\author{
Michel van Kruchten ${ }^{1}$, Erik F.J. de Vries ${ }^{2}$, Henriette J.G. Arts ${ }^{3}$, Neeltina M. Jager ${ }^{1}$, Alphons H.H. Bongaerts ${ }^{4}$, \\ Andor W.J.M. Glaudemans ${ }^{2}$, Harry Hollema ${ }^{5}$, Elisabeth G.E. de Vries ${ }^{1}$, Geke A.P. Hospers ${ }^{1}$, and Anna K.L. Reyners ${ }^{1}$ \\ ${ }^{I}$ Department of Medical Oncology, University of Groningen, University Medical Center Groningen, Groningen, The Netherlands; \\ ${ }^{2}$ Nuclear Medicine and Molecular Imaging, University of Groningen, University Medical Center Groningen, Groningen, The \\ Netherlands; ${ }^{3}$ Gynecology, Division of Gynecological Oncology, University of Groningen, University Medical Center Groningen, \\ Groningen, The Netherlands; ${ }^{4}$ Radiology, University of Groningen, University Medical Center Groningen, Groningen, The \\ Netherlands; and ${ }^{5}$ Pathology, University of Groningen, University Medical Center Groningen, Groningen, The Netherlands
}

The estrogen receptor a $(\mathrm{ERa})$ is expressed in approximately $70 \%$ of ovarian cancer tumors. PET of tumor ERa expression with the tracer $16 \mathrm{a}-{ }^{18} \mathrm{~F}$-fluoro-17 $\beta$-estradiol $\left({ }^{18} \mathrm{~F}-\mathrm{FES}\right)$ may be valuable to select ovarian cancer patients for endocrine therapy. The aim of this study was to evaluate the feasibility of ${ }^{18} \mathrm{~F}$-FES PET to determine tumor ERa expression noninvasively in epithelial ovarian cancer patients. Methods: ${ }^{18} \mathrm{~F}-\mathrm{FES}$ PET/CT was performed shortly before cytoreductive surgery. Tumor ${ }^{18} \mathrm{~F}-\mathrm{FES}$ uptake was quantified for all lesions $10 \mathrm{~mm}$ or greater on CT and expressed as maximum standardized uptake value. ${ }^{18} \mathrm{~F}-\mathrm{FES}$ PET/CT findings were compared with histology and immunohistochemistry for ERa, ERß, and progesterone receptor. Receptor expression was scored semiquantitatively using $\mathrm{H}$-scores (percentage of positive tumor cells $\times$ staining intensity). The optimum threshold to discriminate ER-positive and -negative lesions was determined by receiver-operating-characteristic analysis. Results: In the 15 included patients with suspected ovarian cancer, 32 measurable lesions greater than $10 \mathrm{~mm}$ were present on $\mathrm{CT}$. Tumor ${ }^{18} \mathrm{~F}$-FES uptake could be quantified for 28 lesions (88\%), and 4 lesions were visible but nonquantifiable because of high uptake in adjacent tissue. During surgery, histology was obtained of 23 of 28 quantified lesions (82\%). Quantitative ${ }^{18} \mathrm{~F}$ FES uptake correlated with the semiquantitative immunoscore for ERa $(\rho=0.65, P<0.01)$ and weakly with progesterone receptor expression $(\rho=0.46, P=0.03)$ and was not associated with ER $\beta$ expression ( $\rho=0.21, P=0.33$ ). The optimum threshold to discriminate ERa-positive and ERa-negative lesions was a maximum standardized uptake value greater than 1.8 , which provided a $79 \%$ sensitivity, $100 \%$ specificity, and area under the curve of 0.86 (95\% confidence interval, $0.70-1.00)$. In 2 of 7 patients with cytology/histology available at primary diagnosis and at debulking surgery, immunohistochemical ERa expression had changed over time. ${ }^{18} \mathrm{~F}-\mathrm{FES}$ PET was in accordance with histology at debulking surgery but not at primary diagnosis, indicating that ${ }^{18} \mathrm{~F}-\mathrm{FES}$ PET could provide reliable information about current tumor ERa status. Conclusion: ${ }^{18} \mathrm{~F}-\mathrm{FES}$ PET/CT can reliably assess ERa status in epithelial ovarian cancer tumors and metastases noninvasively. Evaluation of the predictive value of

Received Aug. 21, 2014; revision accepted Oct. 28, 2014.

For correspondence or reprints contact: Anna K.L. Reyners, Department of Medical Oncology, University Medical Center Groningen, P.O. Box 30.001, 9700 RB Groningen, The Netherlands.

E-mail: a.k.l.reyners@umcg.nl

Published online Dec. 4, 2014

COPYRIGHT (C 2015 by the Society of Nuclear Medicine and Molecular Imaging, Inc.
${ }^{18}$ F-FES PET/CT for endocrine therapy in epithelial ovarian cancer patients is warranted.

Key Words: estrogen receptor; imaging; ovarian cancer; FES PET

J Nucl Med 2015; 56:50-55

DOI: 10.2967/jnumed.114.147579

$\mathbf{E}$ ethal gynecologic malignancy. Therefore, new therapeutic strategies are urgently needed. The estrogen receptor $\alpha(\mathrm{ER} \alpha)$ is expressed in approximately $70 \%$ of the epithelial ovarian cancer patients and presents a potential drug target for these tumors (1). Other hormone receptors, such as ER $\beta$ and progesterone receptor (PR), are expressed in approximately $75 \%$ and $20 \%$ of the patients, respectively (2). In phase II studies in ovarian cancer patients unselected for $\mathrm{ER} \alpha$ expression, endocrine therapy generated objective responses in up to $19 \%$ and clinical benefit in up to $51 \%$ of the patients (3-7).

Given the relatively low response rate, predictive biomarkers would be valuable to select those patients who are most likely to benefit from endocrine therapy. In breast cancer, the $\mathrm{ER} \alpha$ is a good predictor for response to endocrine agents (8). It therefore seems reasonable to select also ovarian cancer patients for endocrine therapy based on tumor ER $\alpha$ expression. Surprisingly, however, it is currently unknown whether tumor $\mathrm{ER} \alpha$ expression is predictive for treatment response in ovarian cancer. In breast cancer patients, the $\mathrm{ER} \alpha$ can be heterogeneously expressed among lesions within individuals, and $\mathrm{ER} \alpha$ expression can change during the course of disease $(9,10)$. In a retrospective study, $\mathrm{ER} \alpha$ expression was discordant in $32 \%$ of 67 ovarian cancer patients with histology from both the primary tumor and a synchronous omental metastasis (2). A noninvasive method to quantify $\mathrm{ER} \alpha$ expression in multiple metastases and at different time points might therefore be a valuable asset.

Whole-body imaging of tumor $\mathrm{ER} \alpha$ expression could provide such information. It can be performed by PET with the tracer $16 \alpha-{ }^{18} \mathrm{~F}$-fluoro-17 $\beta$-estradiol $\left({ }^{18} \mathrm{~F}\right.$-FES) $(11) .{ }^{18} \mathrm{~F}$-FES PET can predict response to endocrine therapy in breast cancer and support patient-tailored therapy $(12,13)$. It is, however, unknown whether ${ }^{18} \mathrm{~F}$-FES PET can also be used to evaluate ER $\alpha$ expression in ovarian cancer tumors and whether ${ }^{18} \mathrm{~F}$-FES PET can predict response to 
endocrine therapy in ovarian cancer patients. Visualization and quantification of ${ }^{18} \mathrm{~F}$-FES uptake in ovarian cancer lesions may be impaired by the high physiologic uptake in the liver, gut, uterus, and bladder. We therefore evaluated the feasibility of ${ }^{18} \mathrm{~F}$-FES PET/CT to accurately determine ER density in lesions of patients with epithelial ovarian cancer.

\section{MATERIALS AND METHODS}

\section{Patients}

Patients diagnosed or with high clinical suspicion of epithelial ovarian cancer were eligible when they had tumor lesions $10 \mathrm{~mm}$ or greater on diagnostic CT. Additional eligibility criteria were an Eastern Cooperative Oncology Group performance score of 2 or less and a postmenopausal status. Patients with a history of ER-positive malignancy (breast cancer, endometrial cancer) and patients using antiestrogenic drugs were excluded. All patients underwent ${ }^{18} \mathrm{~F}-\mathrm{FES}$ $\mathrm{PET} / \mathrm{CT}$. Tumor tissue for histology was prospectively collected during surgery performed shortly after ${ }^{18} \mathrm{~F}$-FES PET/CT imaging. Patients were allowed to have received neoadjuvant chemotherapy consisting of carboplatin/paclitaxel before ${ }^{18} \mathrm{~F}-\mathrm{FES}$ PET/CT imaging. In these patients, ${ }^{18} \mathrm{~F}$-FES PET/CT was performed after the last cycle of neoadjuvant chemotherapy and just before surgery. The Committee on Ethics of the University of Groningen approved this study, and all subjects signed a written informed consent form. The study is registered in the ClinicalTrials.gov database (NCT01439490).

\section{CT and ${ }^{18}$ F-FES PET/CT Imaging}

All patients underwent diagnostic CT to identify tumor lesions. ${ }^{18} \mathrm{~F}$ FES was produced as previously described (14). Patients received approximately $200 \mathrm{MBq}$ of ${ }^{18} \mathrm{~F}$-FES intravenously. Whole-body ${ }^{18} \mathrm{~F}-$ FES PET/CT was performed $60 \mathrm{~min}$ after tracer injection, using a Biograph 64-slice mCT (PET/CT) camera (Siemens CTI) with 2-mm reconstructed spatial resolution and an emission acquisition time of $3 \mathrm{~min}$ per bed position. Low-dose CT (for attenuation and scatter correction) and PET imaging were performed sequentially within 1 procedure. Patients for whom the diagnostic CT scan was 6 wk or older at the moment of the ${ }^{18} \mathrm{~F}$-FES PET/CT also underwent a new diagnostic $\mathrm{CT}$ scan in the same procedure. CT scans were evaluated by an experienced radiologist and used to allocate tumor lesions of $10 \mathrm{~mm}$ or greater. This threshold was chosen to limit partialvolume effects and resolution limitations during quantification of ${ }^{18} \mathrm{~F}$ FES uptake. Tumor ${ }^{18} \mathrm{~F}$-FES uptake was quantified by a nuclear medicine physician experienced in ${ }^{18} \mathrm{~F}-\mathrm{FES}$ PET imaging and according to the European Association of Nuclear Medicine guidelines for tumor lesions of $10 \mathrm{~mm}$ or greater, using fused PET/CT images (15). In line with previous studies, we used the maximum standardized uptake value $\left(\mathrm{SUV}_{\max }\right)$ to calculate tumor ${ }^{18} \mathrm{~F}$-FES uptake $(12,13)$. As an explorative analysis, we also measured the mean SUV ( $\left.\mathrm{SUV}_{\text {mean }}\right)$ using a $70 \%$ isocontour of the hottest pixel (16). Concurrent with ${ }^{18} \mathrm{~F}$-FES PET/CT, venous blood was collected from the infusion site (before ${ }^{18} \mathrm{~F}-\mathrm{FES}$ injection) to evaluate serum estradiol and sex hormonebinding globulin, because these have been reported to negatively affect tumor ${ }^{18} \mathrm{~F}$-FES uptake in breast cancer studies $(11,17)$.

\section{Tumor Histology}

All patients were scheduled for cytoreductive surgery aimed at complete debulking of all macroscopic tumor lesions. The locations of resected tumor lesions were recorded to allow comparison between pathology and imaging results. All tumor lesions and macroscopic diameters at pathologic examination were listed in a database. Slides for histologic examination were prepared from all parts with suspected tumor. Hematoxylin and eosin staining was used to evaluate the presence of tumor cells in the resected tissue, and tumors were typed and graded. For all tumor lesions $10 \mathrm{~mm}$ or greater for which quantitative ${ }^{18} \mathrm{~F}$-FES uptake was available, additional immunohistochemistry was performed. Paraffin-embedded formalin-fixed tumor blocks were sliced and mounted on 3-aminopropyltriethoxylanecoated glass slides. Immunohistochemistry was performed as previously described. Briefly, ER $\alpha$ was stained using the clinical-grade SP1 monoclonal rabbit anti-ER $\alpha$ antibody (Ventana) and PR using 1E2 monoclonal rabbit anti-PR antibody (Ventana) in the automated slide stainer with an iView DAB Detection kit (Ventana). ER $\beta$ was stained using a monoclonal mouse anti-ER $\beta 1$ clone PPG5/10 (Serotec).

\section{Immunohistochemical Analysis}

Two independent observers scored the slides for percentage of positive cells $(0 \%-100 \%)$ and staining intensity $(0$, none; 1 , weak; 2 , moderate; and 3, strong) $(18,19)$. For dichotomous classification of receptor positivity, $10 \%$ or more of tumor cells with moderate or strong staining was used as cutoff point in reference to other studies in ovarian cancer (20). For semiquantitative analysis, the percentage of positive cells and staining intensity scores were multiplied to obtain the H-score (range, 0-300) (21). To allow correction for tumor cell density, the percentage tumor and stromal tissue were estimated in a $1 \mathrm{~cm}^{2}$ field of view. Dichotomous immunohistochemistry results, $\mathrm{H}$-scores, and ER density were compared with dichotomous and quantitative tumor ${ }^{18} \mathrm{~F}-\mathrm{FES}$ uptake. Additionally, the association among serum CA-125, estradiol, and sex hormone-binding globulin with tumor ${ }^{18}$ F-FES uptake was evaluated.

\section{Statistical Analysis}

In this pilot study, we aimed to enroll approximately 15 patients to ensure the inclusion of at least 8 patients with ER $\alpha$-positive histology. A sensitivity of ${ }^{18} \mathrm{~F}$-FES PET/CT of $85 \%$ or more was anticipated. A stopping-rule was therefore applied when 4 or more of 8 patients with ER-positive histology did not show tumor ${ }^{18} \mathrm{~F}$-FES uptake $\left(\mathrm{SUV}_{\max }<\right.$ 1.5), because this results in a $95 \%$ confidence interval below $85 \%$ sensitivity. Receiver-operating-characteristic analysis was performed to identify the optimum threshold to differentiate between ER $\alpha$ positive and ER $\alpha$-negative lesions. Sensitivity, specificity, and 95\% confidence intervals were calculated. The Mann-Whitney $U$ test was performed to evaluate differences in ${ }^{18} \mathrm{~F}$-FES uptake between receptor $(\mathrm{ER} \alpha, \mathrm{ER} \beta, \mathrm{PR})$-positive and -negative tumors. A Spearman correlation coefficient was determined to evaluate the correlation between quantitative tumor ${ }^{18} \mathrm{~F}$-FES uptake and semiquantitative measures of receptor expression and the correlation with serum estradiol and sex hormone-binding globulin.

\section{RESULTS}

\section{Patient Characteristics}

Fifteen patients were included between October 2011 and October 2013. One patient had a carcinosarcoma at pathologic examination and was therefore excluded from further analyses. Of the remaining 14 patients, 13 had serous carcinoma and 1 carcinoma of the transitional cell type. Patients had International Federation of Gynecology and Obstetrics stage III $(n=11)$, IV $(n=2)$, and recurrent ovarian cancer $(n=1)$. Nine $(64 \%)$ of the 14 patients received 3 cycles of neoadjuvant chemotherapy before ${ }^{18} \mathrm{~F}$-FES PET/CT imaging. ${ }^{18} \mathrm{~F}$-FES PET/CT imaging was performed at a median of $9 \mathrm{~d}$ before cytoreductive surgery (range, 1-22 d). All patients had postmenopausal serum estradiol levels at the time of ${ }^{18} \mathrm{~F}$-FES PET/CT (median, $0.04 \mathrm{nmol} / \mathrm{L}$; range, $0.02-$ $0.06 \mathrm{nmol} / \mathrm{L}$ ) in accordance with the inclusion criteria. Serum CA-125 levels varied greatly at the time of ${ }^{18} \mathrm{~F}-\mathrm{FES} \mathrm{PET/CT}$ (median, $138 \mathrm{kU} / \mathrm{L}$; range, 18-1,771 kU/L). Patient characteristics are shown in Table 1. 
TABLE 1

Patient Characteristics $(n=14)$

\begin{tabular}{|c|c|}
\hline Characteristic & $n$ \\
\hline \multicolumn{2}{|l|}{ Age (y) } \\
\hline Median & 67 \\
\hline Range & $57-82$ \\
\hline \multicolumn{2}{|c|}{$\begin{array}{l}\text { International Federation of Gynecology } \\
\text { and Obstetrics stage }\end{array}$} \\
\hline IIIC & 11 \\
\hline IV & 2 \\
\hline Recurrent & 1 \\
\hline \multicolumn{2}{|l|}{ Therapy before ${ }^{18} \mathrm{~F}$-FES PET } \\
\hline None & 5 \\
\hline Neoadjuvant chemotherapy & 9 \\
\hline \multicolumn{2}{|l|}{ Histologic subtype } \\
\hline High-grade serous & 13 \\
\hline Transitional cell & 1 \\
\hline \multicolumn{2}{|c|}{ Serum tumor marker Ca-125 (kU/L) } \\
\hline Median & 138 \\
\hline Range & $18-1,771$ \\
\hline \multicolumn{2}{|l|}{ Serum estradiol (nmol/L) } \\
\hline Median & 0.04 \\
\hline Range & $0.02-0.06$ \\
\hline \multicolumn{2}{|c|}{ Serum sex hormone-binding globulin (nmol/L) } \\
\hline Median & 67 \\
\hline Range & $37-142$ \\
\hline
\end{tabular}

\section{${ }^{18}$ F-FES PET/CT Findings}

All patients had a diagnostic contrast-enhanced CT scan available. All patients underwent ${ }^{18} \mathrm{~F}$-FES PET with coregistration of a low-dose CT. Of the 14 patients, 2 patients underwent a new diagnostic $\mathrm{CT}$ at the time of ${ }^{18} \mathrm{~F}-\mathrm{FES}$ PET/CT imaging; the remaining 12 patients had a diagnostic CT scan available that was made less than $6 \mathrm{wk}$ (median, $28 \mathrm{~d}$; range, 7-41 d) before ${ }^{18}$ F-FES PET/CT imaging.

On ${ }^{18}$ F-FES PET/CT, 12 of 14 patients had lesions with ${ }^{18} \mathrm{~F}$ FES uptake. Thirty-two lesions of $10 \mathrm{~mm}$ or greater were identified on ${ }^{18}$ F-FES PET/CT. Four additional lesions were larger than $10 \mathrm{~mm}$ on earlier diagnostic CT but could not be identified on the low-dose CT at the time of ${ }^{18} \mathrm{~F}$-FES PET/CT imaging. These 4 lesions were, however, present in patients who had received 3

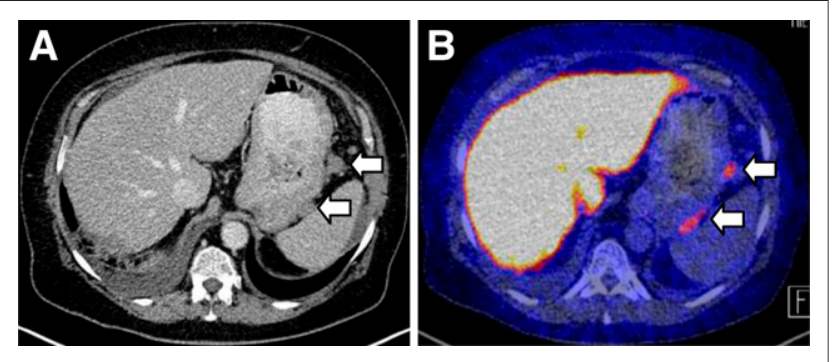

FIGURE 1. Imaging of patient with metastatic lesions between stomach and spleen (arrows): CT scan (A) and ${ }^{18}$ F-FES PET/CT (B). cycles of neoadjuvant chemotherapy at the time of ${ }^{18} \mathrm{~F}$-FES $\mathrm{PET} / \mathrm{CT}$, and all 4 lesions were confirmed to have become less than $10 \mathrm{~mm}$ due to neoadjuvant chemotherapy at pathologic examination. Finally, 4 lesions were visible on ${ }^{18}$ F-FES PET/CT, but ${ }^{18} \mathrm{~F}-\mathrm{FES}$ uptake could not be reliably quantified because of high physiologic background uptake near the lesion (e.g., in the liver, uterus, and intestines). Therefore, 28 lesions, consisting of 12 ovarian tumors and 16 intraabdominal metastases, were used for ${ }^{18} \mathrm{~F}-\mathrm{FES}$ PET/CT analysis. Examples of positive ${ }^{18} \mathrm{~F}-\mathrm{FES}$ PET/CT images of abdominal metastases are provided in Figure 1. There were no new lesions discovered on ${ }^{18} \mathrm{~F}$-FES PET/CT that had not yet been recorded on diagnostic CT. One patient had a newly diagnosed pleural effusion, which harbored increased ${ }^{18} \mathrm{~F}$-FES uptake. Mean tumor $\mathrm{SUV}_{\max }$ of all quantified lesions was 2.4 (range, 1.1-5.1). It was noted that ${ }^{18} \mathrm{~F}$-FES uptake was absent in cystic parts of the tumor lesions (Fig. 2). Although not a primary aim of our study, it was noted that fusion of PET with the diagnostic CT was crucial for identification of the tumor lesions, because tissue surrounding the lesions, such as the uterus, bladder, and intestines, harbored high physiologic uptake.

\section{Concordance Between ${ }^{18}$ F-FES PET/CT and Pathology}

Concurrent histology was available for $23(82 \%)$ of 28 lesions quantified on ${ }^{18} \mathrm{~F}$-FES PET/CT. Histology was not available for the remaining lesions because of inability to perform a complete debulking during surgery. ER $\alpha$ was positive in 19 of 23 lesions $(83 \%)$, with a median $\mathrm{H}$-score of 101 (range, 0-300); ER $\beta$ was positive in 13 lesions $(57 \%)$, with a median H-score of 84 (range, 0-300); and PR was positive in 10 lesions (43\%), with a median $\mathrm{H}$-score of 65 (range, 0-188). Examples of ER $\alpha, E R \beta$, and PR immunostaining are provided in Figure 3.

Tumor ${ }^{18} \mathrm{~F}$-FES uptake was higher in ER $\alpha$-positive lesions than in $\mathrm{ER} \alpha$-negative lesions $\left(\mathrm{SUV}_{\max }, 2.8 \pm 1.3\right.$ vs. $1.4 \pm 0.3$, $P=0.03)$. The optimum threshold for quantitative ${ }^{18} \mathrm{~F}-\mathrm{FES}$ PET imaging to discriminate between $\mathrm{ER} \alpha$-positive and $\mathrm{ER} \alpha$-negative lesions, as determined by receiver-operating-characteristic analysis, was an $\mathrm{SUV}_{\text {max }}$ of 1.8. Application of this threshold resulted in a $100 \%$ specificity (4/4 lesions with uptake $<1.8$ were ER $\alpha$-negative) and $79 \%$ sensitivity $(15 / 19$ lesions with uptake $>1.8$ were $\mathrm{ER} \alpha$-positive). Also, when this threshold was used, 1 patient had both ${ }^{18} \mathrm{~F}$-FES-positive and ${ }^{18} \mathrm{~F}$-FES-negative lesions.

Mean tumor ${ }^{18} \mathrm{~F}$-FES uptake did not differ significantly between ER $\beta$-positive and ER $\beta$-negative lesions $\left(\mathrm{SUV}_{\max }, 2.9 \pm 1.4 \mathrm{vs}\right.$. $2.1 \pm 1.0, P=0.19)$ and between PR-positive and PR-negative lesions $\left(\mathrm{SUV}_{\max }, 3.1 \pm 1.5\right.$ vs. $\left.2.1 \pm 0.8, P=0.17\right)$. As expected, ${ }^{18}$ F-FES PET/CT was not suitable to differentiate between ER $\beta$ positive and ER $\beta$-negative lesions, with a calculated sensitivity of
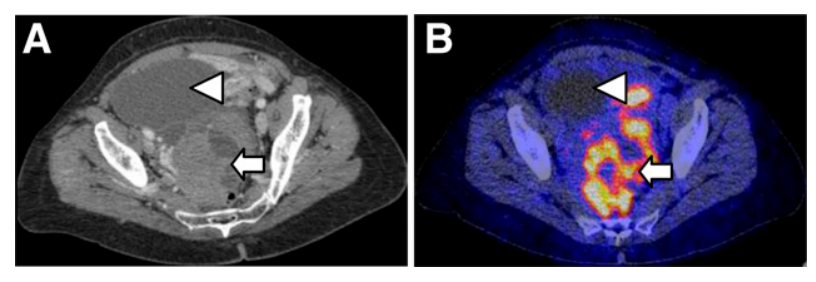

FIGURE 2. CT (A) and ${ }^{18} \mathrm{~F}-\mathrm{FES}$ PET/CT (B) findings of same patient as shown in Figure 3. ERa expression was high and tumor ${ }^{18} \mathrm{~F}$-FES uptake $\left(S_{U V} V_{\max }\right)$ was 5.1. ${ }^{18} \mathrm{~F}$-FES uptake was absent in cystic parts of tumor lesion (arrowhead) when compared with solid parts (arrow). 


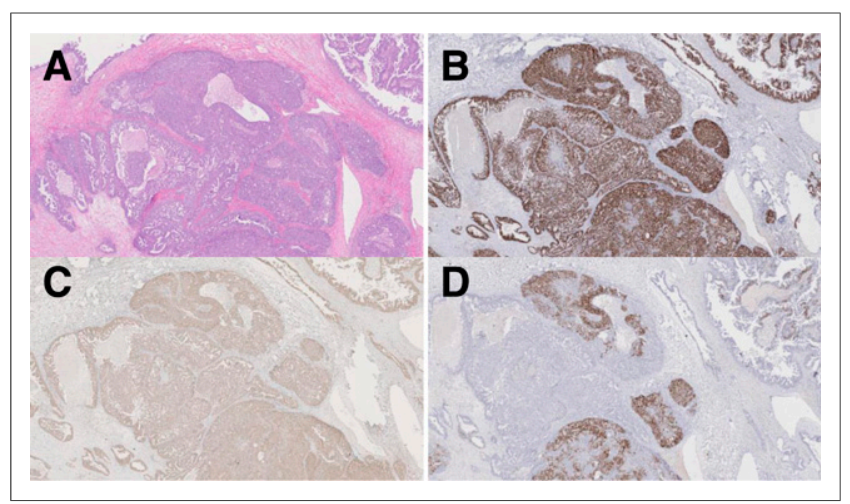

FIGURE 3. Representative examples of hematoxylin and eosin (A), $E R a(B), E R \beta(C)$, and PR (D) staining. In this patient, ERa expression was high, ER $\beta$ was moderately expressed, and PR was heterogeneously expressed.

$77 \%$ and specificity of $50 \%$. The calculated sensitivity and specificity of ${ }^{18} \mathrm{~F}$-FES PET/CT for PR-positive lesions were $70 \%$ and $38 \%$, respectively. The use of $\mathrm{SUV}_{\text {mean }}$ instead of $\mathrm{SUV}_{\max }$ did not affect the sensitivity and specificity of ${ }^{18} \mathrm{~F}$-FES PET for ER $\alpha$ positive lesions, with an $\mathrm{SUV}_{\text {mean }}$ of 1.3 or greater as the optimum threshold to discriminate between $\mathrm{ER} \alpha$-positive and $\mathrm{ER} \alpha$-negative lesions.

In 7 patients with histology at primary diagnosis, and at debulking surgery after neoadjuvant chemotherapy, paired samples were available to evaluate temporal discordance in $\mathrm{ER} \alpha$ expression. In 2 patients (29\%), there was discordant ER $\alpha$ expression. Both patients had $\mathrm{ER} \alpha$-negative immunohistochemistry at diagnosis, ${ }^{18}$ F-FES PET/CT showed ${ }^{18}$ F-FES-positive lesions, and subsequent histology obtained during debulking surgery shortly thereafter was $\mathrm{ER} \alpha$-positive.

\section{Correlation Between Quantitative ${ }^{18}$ F-FES PET/CT and Receptor Expression}

Quantitative tumor ${ }^{18} \mathrm{~F}$-FES uptake $\left(\mathrm{SUV}_{\max }\right)$ correlated well with the H-score for $\mathrm{ER} \alpha(\rho=0.65, P<0.01$, Fig. $4 \mathrm{~A}) .{ }^{18} \mathrm{~F}-$ FES uptake showed a weak correlation with PR expression $(\rho=$ $0.46, P=0.03$, Fig. 4B) and was not associated with ER $\beta$ expression ( $\rho=0.21, P=0.33$, Fig. $4 C$ ). The weak correlation observed between ${ }^{18} \mathrm{~F}$-FES uptake and PR expression can likely be explained by the fact that increased ER $\alpha$ expression correlated with increased PR expression $(\rho=0.54, P<0.01)$ because PR is an ER $\alpha$-mediated estrogen-responsive gene. Indeed, median $\mathrm{SUV}_{\max }$ was 3.8 in PR-positive tumors that were also ER $\alpha$-positive ( $n=8$ lesions) and only 1.2 in PR-positive tumors that were ER $\alpha$ negative ( $n=2$ lesions).
The use of $\mathrm{SUV}_{\text {mean }}$ instead of $\mathrm{SUV}_{\text {max }}$ provided a slightly better correlation between quantitative tumor ${ }^{18} \mathrm{~F}$-FES uptake and $\mathrm{ER} \alpha$ expression $(\rho=0.75, P<0.01)$. Also PR correlated with tumor $\operatorname{SUV}_{\text {mean }}(\rho=0.55, P<0.01)$, whereas ER $\beta$ expression did not correlate with tumor ${ }^{18} \mathrm{~F}-\mathrm{FES}$ uptake using $\mathrm{SUV}_{\text {mean }}$ ( $\rho=0.30, P<0.01)$.

In 4 lesions of 2 patients treated with neoadjuvant chemotherapy, quantitative tumor ${ }^{18} \mathrm{~F}$-FES uptake was low, whereas tumor cells were clearly ER $\alpha$-positive. In these 2 patients, however, the tumors had a relatively low percentage of vital tumor cells. The lower ER density per $\mathrm{cm}^{2}$ therefore likely explains these falsenegative findings (Fig. 5).

\section{Correlation Between Quantitative ${ }^{18} \mathrm{~F}-\mathrm{FES}$ PET/CT and Serum Estradiol and Sex Hormone-Binding Globulin}

All patients had postmenopausal serum estradiol levels. Within the postmenopausal range, there was no trend toward lower ${ }^{18} \mathrm{~F}$ FES uptake in individuals with higher serum estradiol levels $(\rho=$ $0.06, P=0.56$ ). Increased sex hormone-binding globulin levels were reported to negatively affect tumor ${ }^{18} \mathrm{~F}$-FES uptake in larger breast cancer studies (17). In our study, high serum sex hormonebinding globulin levels did not correlate with lower tumor ${ }^{18} \mathrm{~F}-\mathrm{FES}$ uptake $(\rho=-0.18, P=0.59)$.

\section{DISCUSSION}

This is the first study, to our knowledge, that showed that ${ }^{18} \mathrm{~F}$ FES PET/CT can reliably assess tumor $\mathrm{ER} \alpha$ status in patients with epithelial ovarian cancer. Twelve of 14 patients had tumor lesions with an increased ${ }^{18} \mathrm{~F}$-FES uptake.

To the best of our knowledge, no earlier studies describing ${ }^{18}$ F-FES PET/CT in ovarian cancer are available, apart from 1 preliminary case report of ${ }^{18} \mathrm{~F}$-FES PET in a patient with ovarian cancer and leiomyoma in a review article that indicated that ${ }^{18} \mathrm{~F}$ FES uptake can be observed in ovarian cancer (22).

In our feasibility study, we learned several aspects that can be of relevance for future ${ }^{18} \mathrm{~F}$-FES PET studies in ovarian cancer patients. First, we showed that ${ }^{18}$ F-FES uptake was absent in the cystic parts of lesions and therefore a sufficiently large (e.g., $>10$ $\mathrm{mm}$ ) solid component is required for quantification of tumor ${ }^{18} \mathrm{~F}$ FES uptake. Second, in contrast to breast cancer, for which ${ }^{18} \mathrm{~F}$ FES-positive lesions can usually readily be observed also without a concurrent CT scan (23), in this study, ovarian cancer lesions had to be allocated using a concurrent or recent contrast-enhanced diagnostic CT scan. This limitation is because most lesions develop in the abdominal cavity, in which visualization is hampered by high physiologic background tracer levels in the liver, gallbladder, intestines, uterus, kidneys, and bladder (24). Finally, our study design allowed the inclusion of patients who had received neoadjuvant chemotherapy, which has potentially affected tumor ${ }^{18}$ F-FES uptake. The inclusion of neoadjuvant-treated patients with high-stage disease allowed us to obtain both ${ }^{18} \mathrm{~F}$-FES PET/CT data and concurrent histology of multiple lesions from the same patient, which was also one of the strengths of our study. In 2 of 9 of neoadjuvant-treated patients, however, all lesions larger than 10 $\mathrm{mm}$ on earlier diagnostic CT scans were reduced in size to less than $10 \mathrm{~mm}$ due to chemotherapy effects precluding the
FIGURE 4. Correlation between quantitative tumor ${ }^{18} \mathrm{~F}-\mathrm{FES}$ uptake $\left(\mathrm{SUV}_{\max }\right)$ and semiquantitative immunoscore ( $\mathrm{H}$-score) for tumor ERa expression (A), ER $\beta$ expression (B), and PR expression (C).

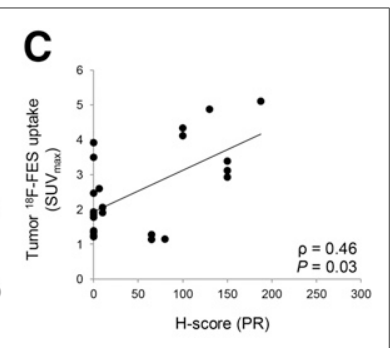




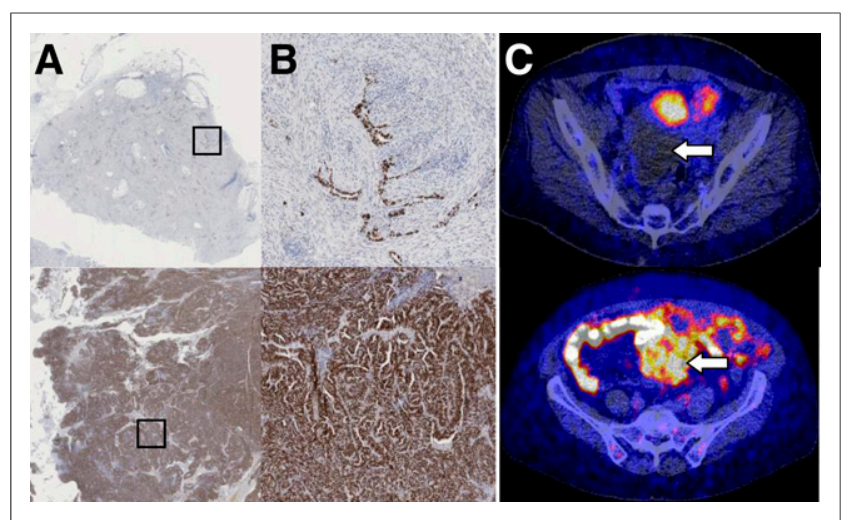

FIGURE 5. Example of patient with false-negative ${ }^{18} \mathrm{~F}$-FES PET/CT findings (upper) and true-positive ${ }^{18} \mathrm{~F}-\mathrm{FES} \mathrm{PET} / \mathrm{CT}$ findings (lower). (A) $1 \mathrm{~cm}^{2}$ overview of ERa staining. (B) $1 \mathrm{~mm}^{2}$ overview of ERa staining of indicated area in A. (C) Corresponding ${ }^{18} \mathrm{~F}-\mathrm{FES} \mathrm{PET} / \mathrm{CT}$ findings. Arrows indicate tumor mass. ${ }^{18} \mathrm{~F}$-FES uptake $\left(\mathrm{SUV}_{\max }\right)$ was 1.3 in tumor shown in upper panel and 4.9 in lower panel. Low tumor cell density in upper panel likely explains negative findings on ${ }^{18} \mathrm{~F}-\mathrm{FES} \mathrm{PET/CT}$.

assessment at the time of ${ }^{18} \mathrm{~F}$-FES PET. In 2 other neoadjuvanttreated patients, 4 lesions greater than $10 \mathrm{~mm}$ harbored only a few vital tumor cells at pathologic examination. Thus, antitumor effects in patients treated with neoadjuvant chemotherapy may have affected ${ }^{18}$ F-FES PET sensitivity.

To date, most ${ }^{18} \mathrm{~F}$-FES PET studies have used $\mathrm{SUV}_{\max }$ to quantify tumor ${ }^{18} \mathrm{~F}-\mathrm{FES}$ uptake (11). This method of quantification has several advantages, among which is its easy reproducibility. As an explorative analysis, we also measured $\mathrm{SUV}_{\text {mean }}$ using an arbitrary $70 \%$ isocontour. Although this slightly increased the correlation between tumor ${ }^{18} \mathrm{~F}$-FES uptake $\left(\mathrm{SUV}_{\text {mean }}\right)$ and $\mathrm{ER} \alpha$ expression, it did not result in a better sensitivity and specificity. The most optimum way to quantify tumor ${ }^{18} \mathrm{~F}$-FES uptake, using $\mathrm{SUV}_{\max }$ or $\mathrm{SUV}_{\text {mean }}$ with a percentage isocontour, with or without correction for background physiologic ${ }^{18}$ F-FES uptake needs to be addressed in future studies.

The current gold standard to determine hormone receptor expression is immunohistochemistry. This standard has some limitations in patients with metastatic disease, including possible difficulty in obtaining a biopsy because of, for example, the location of the lesion. Also, determining the current ER status of the patient on stored tissue samples can be unreliable because of changes in ER expression over time. Finally, because of intratumor and intertumor heterogeneity, a biopsy may not always reflect actual ER status. These issues have especially been shown to play a role in breast cancer $(9,10)$ but may also apply to ovarian cancer. Specifically, we showed previously that heterogeneous ER expression among lesions within the same individual does also exist in ovarian cancer (2). In the current study, in 2 of 7 patients with biopsies at diagnosis and at surgery several months later, discordant $\mathrm{ER} \alpha$ expression was observed. Because the first biopsy was performed as a diagnostic procedure before inclusion in the study, we were unable to precisely determine which lesion was biopsied. Therefore, the discordance might be explained by heterogeneity between lesions or by changes in ER expression, for example, because of neoadjuvant chemotherapy effects. Either way, this difference illustrates that a single tumor biopsy may not always reliably reflect $\mathrm{ER} \alpha$ status during the course of disease.

${ }^{18} \mathrm{~F}-\mathrm{FES}$ PET has previously been evaluated to assess ER status in breast cancer metastases, which showed a good sensitivity of $84 \%$ and excellent specificity of $98 \%(11,25-28)$. In addition, ${ }^{18}$ F-FES PET was shown to be a predictive biomarker for response to antihormonal therapy in various studies in metastatic breast cancer patients $(12,13,29)$. In ovarian cancer patients, the role of endocrine therapy is limited. Objective tumor responses to endocrine agents are observed in $8 \%-19 \%$ of heavily pretreated patients in several phase II studies (4,5,30-32). But surprisingly, these studies did not generally select patients based on ER expression by their tumor. In a retrospective study in 26 patients with ovarian cancer treated with the pure ER antagonist fulvestrant, higher levels of ER expression by the tumor were associated with clinical benefit (33).

\section{CONCLUSION}

${ }^{18} \mathrm{~F}$-FES PET/CT can reliably assess ER $\alpha$ status in epithelial ovarian cancer tumors and metastases noninvasively, with a $79 \%$ sensitivity and $100 \%$ specificity. On the basis of the findings of this study, exploration of the value of ${ }^{18} \mathrm{~F}$-FES PET to predict treatment response to endocrine agents is warranted. Ideally, patients with ovarian cancer presenting with especially solid tumor lesions larger than $10 \mathrm{~mm}$ seem candidates for evaluating the potential of ${ }^{18} \mathrm{~F}-\mathrm{FES}$ $\mathrm{PET} / \mathrm{CT}$ as a predictive imaging biomarker.

\section{DISCLOSURE}

The costs of publication of this article were defrayed in part by the payment of page charges. Therefore, and solely to indicate this fact, this article is hereby marked "advertisement" in accordance with 18 USC section 1734 . This study was supported by a grant from the Dutch Cancer Society, RUG 2009-4529. No other potential conflict of interest relevant to this article was reported.

\section{REFERENCES}

1. Sieh W, Kobel M, Longacre TA, et al. Hormone-receptor expression and ovarian cancer survival: an ovarian tumor tissue analysis consortium study. Lancet Oncol. 2013;14:853-862.

2. van Kruchten M, van der Marel PW, Arts HJG, et al. Frequency and prognostic value of hormone receptor expression in epithelial ovarian cancer [abstract]. Cancer Res. 2013;73(suppl 1):4768.

3. Hasan J, Ton N, Mullamitha S, et al. Phase II trial of tamoxifen and goserelin in recurrent epithelial ovarian cancer. Br J Cancer. 2005;93:647-651.

4. Argenta PA, Thomas SG, Judson PL, et al. A phase II study of fulvestrant in the treatment of multiply-recurrent epithelial ovarian cancer. Gynecol Oncol. 2009;113:205-209.

5. Papadimitriou CA, Markaki S, Siapkaras J, et al. Hormonal therapy with letrozole for relapsed epithelial ovarian cancer: long-term results of a phase II study. Oncology. 2004;66:112-117.

6. Wilailak S, Linasmita V, Srisupundit S. Phase II study of high-dose megestrol acetate in platinum-refractory epithelial ovarian cancer. Anticancer Drugs. 2001;12:719-724.

7. Bowman A, Gabra H, Langdon SP, et al. CA125 response is associated with estrogen receptor expression in a phase II trial of letrozole in ovarian cancer: identification of an endocrine-sensitive subgroup. Clin Cancer Res. 2002;8:2233-2239.

8. Early Breast Cancer Trialists' Collaborative Group (EBCTCG), Davies C, Godwin J, et al. Relevance of breast cancer hormone receptors and other factors to the efficacy of adjuvant tamoxifen: patient-level meta-analysis of randomised trials. Lancet. 2011;378:771-784.

9. Amir E, Miller N, Geddie W, et al. Prospective study evaluating the impact of tissue confirmation of metastatic disease in patients with breast cancer. $J$ Clin Oncol. 2012;30:587-592.

10. Lindström LS, Karlsson E, Wilking UM, et al. Clinically used breast cancer markers such as estrogen receptor, progesterone receptor, and human epidermal growth factor receptor 2 are unstable throughout tumor progression. J Clin Oncol. 2012;30:2601-2608.

11. van Kruchten M, de Vries EG, Brown M, et al. PET imaging of oestrogen receptors in patients with breast cancer. Lancet Oncol. 2013;14:e465-e475.

12. Linden HM, Stekhova SA, Link JM, et al. Quantitative fluoroestradiol positron emission tomography imaging predicts response to endocrine treatment in breast cancer. J Clin Oncol. 2006;24:2793-2799. 
13. Mortimer JE, Dehdashti F, Siegel BA, Trinkaus K, Katzenellenbogen JA, Welch MJ. Metabolic flare: indicator of hormone responsiveness in advanced breast cancer. J Clin Oncol. 2001;19:2797-2803.

14. Roemer J, Steinbach J, Kasch H. Studies on the synthesis of $16 \alpha-\left[{ }^{18} \mathrm{~F}\right]$ fluoroestradiol. Appl Radiat Isot. 1996;47:395-399.

15. Boellaard R, O'Doherty MJ, Weber WA, et al. FDG PET and PET/CT: EANM procedure guidelines for tumour PET imaging: version 1.0. Eur J Nucl Med Mol Imaging. 2010;37:181-200.

16. Boellaard R, Krak NC, Hoekstra OS, Lammertsma AA. Effects of noise, image resolution, and ROI definition on the accuracy of standard uptake values: a simulation study. J Nucl Med. 2004;45:1519-1527.

17. Peterson LM, Kurland BF, Link JM, et al. Factors influencing the uptake of ${ }^{18} \mathrm{~F}$ fluoroestradiol in patients with estrogen receptor positive breast cancer. $\mathrm{Nucl}$ Med Biol. 2011;38:969-978.

18. Burges A, Bruning A, Dannenmann C, et al. Prognostic significance of estrogen receptor alpha and beta expression in human serous carcinomas of the ovary. Arch Gynecol Obstet. 2010;281:511-517.

19. De Stefano I, Zannoni GF, Prisco MG, et al. Cytoplasmic expression of estrogen receptor beta $(E R \beta)$ predicts poor clinical outcome in advanced serous ovarian cancer. Gynecol Oncol. 2011;122:573-579.

20. Jongen V, Briet J, de Jong R, et al. Expression of estrogen receptoralpha and -beta and progesterone receptor-A and -B in a large cohort of patients with endometrioid endometrial cancer. Gynecol Oncol. 2009;112: 537-542.

21. Finn RS, Press MF, Dering J, et al. Quantitative ER and PgR assessment as predictors of benefit from lapatinib in postmenopausal women with hormone receptor-positive, HER-2 negative metastatic breast cancer. Clin Cancer Res. 2014;20:736-743.

22. Yoshida Y, Kurokawa T, Tsujikawa T, Okazawa H, Kotsuji F. Positron emission tomography in ovarian cancer: ${ }^{18} \mathrm{~F}$-deoxy-glucose and $16 \alpha-{ }^{18} \mathrm{~F}$-fluoro- $17 \beta$-estradiol PET. J Ovarian Res. 2009;2:7-16.
23. van Kruchten M, Glaudemans AW, de Vries EF, et al. PET imaging of estrogen receptors as a diagnostic tool for breast cancer patients presenting with a clinical dilemma. J Nucl Med. 2012;53:182-190.

24. Mankoff DA, Peterson LM, Tewson TJ, et al. $\left[{ }^{18} \mathrm{~F}\right]$ fluoroestradiol radiation dosimetry in human PET studies. J Nucl Med. 2001;42:679-684.

25. Mintun MA, Welch MJ, Siegel BA, et al. Breast cancer: PET imaging of estrogen receptors. Radiology. 1988;169:45-48.

26. Mortimer JE, Dehdashti F, Siegel BA, Katzenellenbogen JA, Fracasso P, Welch MJ. Positron emission tomography with 2-[ ${ }^{18}$ F $]$ fluoro-2-deoxy-D-glucose and $16 \alpha-\left[{ }^{18} \mathrm{~F}\right]$ fluoro- $17 \beta$-estradiol in breast cancer: correlation with estrogen receptor status and response to systemic therapy. Clin Cancer Res. 1996;2:933-939.

27. Peterson LM, Mankoff DA, Lawton T, et al. Quantitative imaging of estrogen receptor expression in breast cancer with PET and ${ }^{18} \mathrm{~F}$-fluoroestradiol. $\mathrm{J} \mathrm{Nucl}$ Med. 2008;49:367-374.

28. Dehdashti F, Mortimer JE, Siegel BA, et al. Positron tomographic assessment of estrogen receptors in breast cancer: comparison with FDG-PET and in vitro receptor assays. J Nucl Med. 1995;36:1766-1774.

29. Dehdashti F, Mortimer JE, Trinkaus K, et al. PET-based estradiol challenge as a predictive biomarker of response to endocrine therapy in women with estrogenreceptor-positive breast cancer. Breast Cancer Res Treat. 2009;113:509-517.

30. Markman M, Iseminger KA, Hatch KD, Creasman WT, Barnes W, Dubeshter B. Tamoxifen in platinum-refractory ovarian cancer: a Gynecologic Oncology Group ancillary report. Gynecol Oncol. 1996;62:4-6.

31. Hatch KD, Beecham JB, Blessing JA, Creasman WT. Responsiveness of patients with advanced ovarian carcinoma to tamoxifen: a Gynecologic Oncology Group study of second-line therapy in 105 patients. Cancer. 1991;68:269-271.

32. Smyth JF, Gourley C, Walker G, et al. Antiestrogen therapy is active in selected ovarian cancer cases: the use of letrozole in estrogen receptor-positive patients. Clin Cancer Res. 2007;13:3617-3622.

33. Argenta PA, Um I, Kay C, et al. Predicting response to the anti-estrogen fulvestrant in recurrent ovarian cancer. Gynecol Oncol. 2013;131:368-373. 